Résumés des conférences et travaux

\title{
Initiation aux inscriptions royales assyriennes
}

\section{Lionel Marti}

\section{(2) OpenEdition}

\section{Journals}

Édition électronique

URL : https://journals.openedition.org/ashp/1130

DOI : $10.4000 /$ ashp. 1130

ISSN : 1969-6310

Éditeur

Publications de l'École Pratique des Hautes Études

\section{Édition imprimée}

Date de publication : 1 octobre 2011

Pagination : 7-9

ISSN : 0766-0677

\section{Référence électronique}

Lionel Marti, «Initiation aux inscriptions royales assyriennes », Annuaire de l'École pratique des hautes études (EPHE), Section des sciences historiques et philologiques [En ligne], 142 | 2011, mis en ligne le 23 septembre 2011, consulté le 06 juillet 2021. URL : http://journals.openedition.org/ashp/1130 ; DOI : https://doi.org/10.4000/ashp.1130 


\title{
INITIATION AUX INSCRIPTIONS ROYALES ASSYRIENNES
}

\author{
Chargé de conférences : M. Lionel MARTI
}

Programme de l'année 2009-2010 : Les campagnes extraordinaires des souverains assyriens.

Les conférences de l'année avaient pour sujet « les campagnes extraordinaires des rois d'Assyrie ». Les inscriptions royales assyriennes sont souvent considérées comme répétitives, reprenant toujours les mêmes thèmes, ceux de l'héroïsme du souverain, de la puissance de ses troupes, de la défaite sans appel de ses ennemis et des torrents de sang descendant finalement des montagnes. Néanmoins, à l'époque des Sargonides ( $\mathrm{VIII}^{\mathrm{e}}-\mathrm{VII}^{\mathrm{e}}$ siècles av. J.-C.), le style annalistique connaît un développement sans précédent rendant certains textes véritablement extra-ordinaires. Ceux que nous avons considérés comme tels sont des récits dont le traitement littéraire sort du schéma et de la rhétorique habituels des inscriptions royales assyriennes. Très souvent, par exemple, la confrontation du roi avec la nature, qu'il s'agisse de déserts ou de montagnes, oblitère l'adversaire humain considéré comme partie négligeable de l'action. En quelque sorte, certaines campagnes quittent la description purement militaire pour se transformer en récit de voyage extra-ordinaire.

Le début de l'année a été consacré à l'étude d'inscriptions royales assyriennes typiques, pour pouvoir dans un second temps identifier et aborder des campagnes atypiques.

Le cours a commencé par l'étude comparative de deux petites inscriptions ( $K A H$ 2101 et $102=$ RIMA A.0.102.99) de Salmanazar III (858-824) commémorant des travaux sur la muraille intérieure de la ville d'Aššur, ce qui a permis d'étudier la structure d'une inscription royale simple, comportant la titulature du souverain ainsi que sa filiation et le travail commémoré. Il a été particulièrement intéressant de commenter le jeu des variantes entre ces deux textes ainsi que d'étudier les restitutions possibles dans l'un des textes abîmés grâce aux parallèles conservés.

Nous avons ensuite comparé ces petites inscriptions de trois lignes avec un des récits (RIMA A.0.102.6) des première et deuxième campagnes (comportant quinze lignes) de ce souverain dirigées vers l'ouest. On a pu commenter la structure relativement simple de l'inscription ainsi que l'efficacité du récit, se limitant à la description sommaire des causes de la campagne, du déplacement ainsi que de l'issue de la confrontation qui aboutit à la destruction des forteresses de l'ennemi et au triomphe du souverain.

Après cette brève introduction, le sujet même du cours a été abordé par l'étude de la cinquième campagne du roi Sennachérib, dont un des récits s'étend sur trente-six amples lignes. Cette campagne datée de 697 est dirigée contre la ville de Ukku, située au nord de l'Assyrie dans les montagnes. Parmi les thèmes habituels des inscriptions royales assyriennes s'en intercalent d'autres, qui rendent le développement du récit 
plus long et poétique. Nous voyons notamment les notions d'héroïsme et d'exploit personnel être exprimées. La difficulté de l'expédition est soulignée par les descriptions de traversées d'endroits montagneux, extrêmement étroits et difficiles, que même les rois antérieurs n'avaient pas pratiqués. L'une des particularités des inscriptions de Sennachérib est de donner parfois au roi un visage humain derrière la figure héroïque en exprimant les difficultés qu'il rencontre, contrairement aux topoi habituels où le roi, véritable surhomme, survole les difficultés. Ici, au milieu de la campagne, il se décrit se reposant à même la montagne, buvant l'eau fraîche des outres pour étancher sa soif, ce qui donne à ce moment une sensation de calme, en décalage avec les flots de sang et de violence décrits ailleurs. Le soin porté à la description de l'expédition dans les montagnes et, finalement, l'assez faible part donnée à la description de l'adversaire et du combat font de la montagne elle-même le véritable centre du récit et le seul adversaire à vaincre, réduisant l'ennemi humain à une simple péripétie du déplacement.

Après avoir commenté le récit de cette expédition, nous nous sommes attachés à traduire une des versions de la sixième campagne de ce souverain datant de 694, décrite avec force détails, sur près de cinquante-huit lignes.

Après avoir une nouvelle fois maté une révolte babylonienne, Sennachérib installe son fils aîné Aššur-nâdin-šumi sur le trône de Babylone et, après 5 ans de stabilité, décide de lancer une expédition militaire pour châtier des Babyloniens qui avaient échappé à son courroux et s'étaient réfugiés en Élam. La description de la campagne comporte des passages uniques dans les annales assyriennes. Elle débute par l'explication des raisons de l'intervention assyrienne et se poursuit par la description des préparatifs de l'expédition. Sennachérib fit venir des artisans syriens pour créer des navires «exceptionnels» qu'il arma de marins originaires de la côte méditerranéenne. Il fit descendre sa flotte par le Tigre, puis la transféra sur l'Euphrate. Arrivée au sud de l'empire, l'armée, alors qu'elle campe sur le rivage, est surprise par une tempête et la tente même du souverain est envahie par les flots. Les troupes durent se réfugier dans les bateaux 5 jours et 5 nuits. L'armée arrive finalement à l'embouchure de l'Euphrate, lieu décrit comme véritablement effrayant, où les eaux du fleuve rencontrent la mer déchaînée, ce qui n'empêche pas, après un rituel approprié, de se lancer à l'attaque des positions adverses. Ces dernières sont décrites en détails. Les adversaires des Assyriens ont installé leur ligne de bataille sur les hauteurs le long de la rive, et ils se préparent au combat en aiguisant leurs armes. Les Assyriens cherchent tout d'abord un lieu propice au débarquement. Le récit de la bataille lui-même que l'on attendrait fouillé n'est qu'extrêmement court et se limite à « Ils (= les troupes assyriennes) instaurèrent leur défaite ». La campagne se conclut par la destruction des villes rencontrées et la distribution du butin réuni. Ce récit, comme le précédent, donne l'impression que l'exploit ne réside pas tant dans l'évidente victoire, que dans la lutte contre les éléments pour mener à bien l'expédition.

Cette année, deux séances ont été en outre consacrées à des documentations non royales pour former les étudiants à d'autres types de textes et de supports.

Une séance a été consacrée à l'étude d'un passage d'un texte médical $B A M$ VI 510, commenté par deux spécialistes du genre, les $\mathrm{D}^{\mathrm{r}}$ Annie Attia et Gilles Buisson, que je remercie vivement, car, comme tout texte savant, l'abord en est très difficile lorsqu'on ne dispose pas des clefs d'interprétation. 
La dernière séance de l'année a porté sur l'étude de quelques tablettes cunéiformes conservées à la $\mathrm{IV}^{\mathrm{e}}$ section de l'École pratique des hautes études, de périodes différentes allant de l'époque paléo-babylonienne, en passant par l'époque cassite, à l'époque néo-babylonienne. Les étudiants ont ainsi été confrontés à une documentation originale de diverses époques. Ils ont pu apprendre les bases nécessaires pour aborder ce genre de documentation et mener à bien un véritable travail d'épigraphiste en faisant l'expérience de l'évolution du cunéiforme sur plus d'un millénaire. 